NBER WORKING PAPER SERIES

\title{
CAN STRUCTURAL SMALL OPEN ECONOMY MODELS ACCOUNT FOR THE INFLUENCE OF FOREIGN DISTURBANCES?
}

\author{
Alejandro Justiniano \\ Bruce Preston \\ Working Paper 14547 \\ http://www.nber.org/papers/w14547
NATIONAL BUREAU OF ECONOMIC RESEARCH
1050 Massachusetts Avenue
Cambridge, MA 02138 \\ December 2008
}

First Draft: September 2005. We are grateful to Gunter Coenen, Charles Engel, Jordi Gali, Paulo Giordani, Thomas Lubik, Adrian Pagan, Giorgio Primiceri and two anonymous referees for discussions and detailed comments. We also thank seminar participants at the Atlanta Federal Reserve Bank, Board of Governors of the Federal Reserve, Cleveland Federal Reserve Bank Conference on "DSGE and Factor Models", Duke University conference on "Identification and estimation of structural models", the joint ECB, Lowy Institute and CAMA conference on "Globalization and Regionalism", Reserve Bank of Australia, The Riksbank conference on "Structural Analysis of Business Cycles in the Open Economy" and University of Washington. Preston thanks the PER Seed Grant at Columbia University for financial support. The usual caveat applies. The views expressed in this paper are those of the authors' and should not be interpreted as reflecting the views of the Federal Reserve Bank of Chicago, any other person associated with the Federal Reserve system or the National Bureau of Economic Research.

NBER working papers are circulated for discussion and comment purposes. They have not been peerreviewed or been subject to the review by the NBER Board of Directors that accompanies official NBER publications.

(C) 2008 by Alejandro Justiniano and Bruce Preston. All rights reserved. Short sections of text, not to exceed two paragraphs, may be quoted without explicit permission provided that full credit, including (c) notice, is given to the source. 
Can Structural Small Open Economy Models Account for the Influence of Foreign Disturbances? Alejandro Justiniano and Bruce Preston

NBER Working Paper No. 14547

December 2008

JEL No. F41

\title{
ABSTRACT
}

This paper demonstrates that an estimated, structural, small open economy model of the Canadian economy cannot account for the substantial influence of foreign-sourced disturbances identified in numerous reduced-form studies. The benchmark model assumes uncorrelated shocks across countries and implies that U.S. shocks account for less than 3 percent of the variability observed in several Canadian series, at all forecast horizons. Accordingly, model-implied cross-correlation functions between Canada and U.S. are essentially zero. Both findings are at odds with the data. A specification that assumes correlated cross-country shocks partially resolves this discrepancy, but still falls well short of matching reduced-form evidence.

\author{
Alejandro Justiniano \\ Economic Research Department \\ Federal Reserve Bank of Chicago \\ 230 S. LaSalle Street \\ Chicago, IL 60604 \\ Alejandro.Justiniano@chi.frb.org \\ Bruce Preston \\ Department of Economics \\ Columbia University \\ 420 West 118th Street \\ New York, NY 10027 \\ and NBER \\ bp2121@columbia.edu
}




\section{Introduction}

This paper investigates whether an estimated microfounded semi-small open economy model can reproduce the observed comovements in international business cycles. Focusing on Canada as the small open economy, the starting point for the analysis is the large body of empirical work that identifies a significant influence of U.S. shocks on Canadian economic fluctuations.

There has been ample theoretical work seeking to replicate the observed comovements in economic activity across countries. Until recently, the empirical validation of these models largely relied on calibrations aimed at matching selected moments in the data - see the contributions of Backus et al. (1992, 1995), Stockman and Tesar (1995) and Baxter (1995) for a review. The New Open Economy Macroeconomics (NOEM) has since produced significant theoretical advancements in international macroeconomic modeling. Given the empirical success of closed economy models built on similar foundations, it is not surprising that there is a growing literature estimating NOEM models. These include amongst others: Ambler et al. (2003), Bergin (2003, 2004), Del Negro (2003), Ghironi (2000), Lubik and Schorfheide (2003, 2005), Lubik and Teo (2005) and Rabanal and Tuesta (2005).

To our knowledge, the ability of these NOEM models to explain the observed comovement in economic fluctuations has not been previously systematically analyzed in this empirical literature. This paper fills this gap by evaluating a workhorse semi-small NOEM model in this particular dimension. The focal point is the model's ability to replicate the fraction of the variance in Canadian macroeconomic series attributed to U.S. shocks. We also contrast the cross-country correlation functions in the model and data, particularly for output.

The analysis is pursued using generalizations of the small open economy framework proposed by Gali and Monacelli (2005). ${ }^{1}$ Following Monacelli (2005), we allow for deviations from the law of one price. In addition, we consider incomplete asset markets, a large set of disturbances, and incorporate other real and nominal rigidities (e.g., wage stickiness, indexation and habits) which have been found crucial in fitting closed economy models as documented by Christiano et al. (2005) and Smets and Wouters (2007).

The model is estimated using Bayesian methods with data for Canada and the United

\footnotetext{
${ }^{1}$ The model is technically a semi-small open economy model, where domestic goods producers have some market power, but we shall nonetheless refer to it as a small open economy. Note also that our analysis appeals to an earlier interpretation in Gali and Monacelli (2005) of a small-large country pair, rather than as an analysis of a continuum of small open economies.
} 
States. Our baseline specification assumes that shocks across these two countries are independent. This contrasts with much of the international real business cycle literature which often assumes correlated cross-country technology shocks, but is consistent with all of the empirical NOEM studies cited above. ${ }^{2}$ Under independent shocks, the channels of transmission embedded in the model (e.g. risk sharing and expenditure switching effects) must account for the cross-country comovement in aggregate fluctuations.

The main contribution of this paper is to document that the baseline specification fails to account for the influence of foreign shocks. A structural variance decomposition reveals that all U.S. shocks combined cannot explain more than 3 percent of the variability in Canadian output, interest rates or inflation. Furthermore, model-implied cross-correlation functions between these two countries are estimated to be essentially zero. Both findings are in stark contrast with reduced-form empirical evidence in the same data. These results are shown to be robust across alternative priors and detrending methods.

As comovement readily obtains when the model is calibrated with plausible parameter values, our findings indicate that the inability to reproduce international correlations in output — known as the quantity anomaly in Baxter and Crucini (1995) — is exacerbated in estimated models. Our results also suggest caution in extrapolating to the international dimension the empirical success of related closed economy models. This is important considering the growing reliance on models of this kind for policy analysis.

A second contribution of this paper is to document that the comovement problem can only be partially resolved by introducing disturbances that are correlated across countries. To do this, each Canadian structural shock is written as the sum of two orthogonal components: a disturbance common to the U.S. block and a country-specific shock. This decomposition can be viewed as a rough approximation to reduced-form dynamic factor models that have been used for business cycle analysis. ${ }^{3}$

When all U.S. shocks are common to the domestic block the DSGE model gets closer to matching the reduced-form variance decomposition. However, there are at least three reasons for not viewing this specification as a panacea for the model's inability to replicate

\footnotetext{
${ }^{2}$ For example, Gali and Monacelli (2005) consider the role of technology spillovers in their calibration study. But likelihood-based empirical studies have typically excluded this possibility.

${ }^{3}$ In a closed economy setting, Boivin and Giannoni (2006) establish a formal link between DSGE and dynamic factor models.
} 
the observed influence of foreign disturbances. First, at medium to long horizons, the fraction of output variation explained by U.S. disturbances is still below the reduced-form evidence. Second, this specification engenders an extreme version of the exchange rate disconnect - see Devereux and Engel (2002). Third, some of the induced correlations are difficult to rationalize on structural grounds. Hence, our results indicate ample scope to improve the transmission mechanism of foreign disturbances in this class of models.

This paper broadly relates to the international business cycle literature and recent empirical work with NOEM models. More closely related is Adolfson et al. (2007) who presents a state-of-the-art model, more richly specified than the one considered here. While their model performs very well in several dimensions, an earlier version, Adolfson et al. (2005), reported variance decompositions revealing little transmission of foreign sourced disturbances from the European Union to Sweden - a property that is not remarked upon. Similar observations apply to de Walque et al. (2005) in a two-country model for the U.S. and the Euro Area. We also build on Schmitt-Grohe (1998) who evaluates whether a calibrated small open economy real business cycle model can replicate impulse responses to a single foreign output shock, extracted from a bivariate U.S.-Canada vector autoregression. ${ }^{4}$ Our results suggest once again that in estimation the failure to capture international linkages may be worse than when the model is calibrated.

The remainder of the paper proceeds as follows. Section 2 provides statistical evidence of comovement between the U.S. and Canadian business cycles. Section 3 lays out the theoretical model. Section 4 describes the data and estimation methodology. Parameter estimates are briefly discussed. Section 5 shows that the model fails to account for the influence of foreign disturbances. Section 6 presents robustness checks. Section 7 considers specifications with common shocks. We conclude with some thoughts on the implications of our findings for future work.

\footnotetext{
${ }^{4}$ Schmitt-Grohe (1998) concludes that financial and trade linkages are not capable of reproducing the strong response of Canadian hours, output and investment to innovations in U.S. GNP. She suggests that these difficulties might be alleviated by the introduction of sticky prices. Our analysis reveals that the inability to capture the influence of foreign shocks persists in an estimated model even when various nominal rigidities are considered.
} 


\section{Evidence on International Linkages}

A central empirical regularity that international business cycle models seek to explain is the observed cross-country comovement amongst economic variables. This section documents a number of statistics suggesting comovement is a salient feature of U.S. and Canadian business cycles, understanding that earlier literature testifies to the generality of these insights in other economies. This close link is not surprising considering the U.S. accounts for 75 percent of Canada's average trade share. ${ }^{5}$

\subsection{Data}

We use data for twelve series that in section 4 constitute the observable states in the estimated DSGE model. These are: real per-capita output, inflation, nominal interest rates, real wages and hours in both the U.S. and Canada, as well as the bilateral terms of trade and the real exchange rate. Details of the data are in appendix A. Consistent with the model presented later, output and real wages are expressed in log-deviations from a common linear trend. The real exchange rate and the terms of trade are given in log-differences. Section 6 evidences the robustness of our results to alternative detrending of these series. Inflation and interest rates are expressed as percentages and, like hours, are not transformed, except that all series are demeaned. The sample runs from 1982q1 to 2007q1, although the first 8 quarters are used to initialize the Kalman filter.

\subsection{Reduced-Form Evidence}

The solid black lines in figure 1 give the sample cross-correlations between U.S. and Canadian series at lags zero through four. The remaining lines correspond to the estimated DSGE model and are discussed in section 4. For presentation purposes only we exclude these statistics for the terms of trade and the real exchange rate but discuss them later on.

For many series these cross-correlations are large at various lags and rarely equal to zero. For example, the contemporaneous correlations between Canadian and U.S. output, inflation, nominal interest rates and wages are: $0.69,0.45,0.83$ and 0.72 , respectively. This is consistent with earlier studies on international comovement, such as Backus et al. (1992), Stockman and

\footnotetext{
${ }^{5}$ In our sample, adding $1 / 2$ the share of U.S. imports in total Canadian imports plus $1 / 2$ the share of total Canadian exports oriented to the U.S. equals 75.1 percent.
} 
Tesar (1995) and Ambler at al. (2004).

We rely on two statistical models to compute the variance share of these Canadian series that is attributable to U.S. shocks. The first model is a VAR subject to the exclusion restriction of no feedback from Canada to the U.S. that is embedded in the DSGE model. Hence, it is formally a seemingly unrelated regression (SUR). Variance decompositions are obtained with a Cholesky decomposition of the SUR innovations with no attempt to identify any particular shock. We only wish to infer the variance shares explained by disturbances also affecting the U.S. block. ${ }^{6}$ The SUR is estimated with the efficient block-recursive Gibbs algorithm proposed by Zha (1999). Details are in appendix B.

Table 1 reports variance shares attributable to all foreign shocks in a SUR (with 4 lags) at 1, 4, and 8 quarter horizons, and the stationary (long-horizon) variance. We report medians and 90 percent posterior probability bands. In the short, medium and long run, U.S. disturbances account for a substantial fraction of variation in Canadian series. For example, at a 4 quarter horizon, shares vary from 25 percent for hours to 44 percent for output. At long horizons, contributions vary from 65 percent for inflation to 76 percent for output. The latter is almost identical to the 74 percent share for U.S. shocks in the smaller, but overidentified, structural SUR model of Cushman and Zha (1997).

The SUR analysis is limited by sample considerations to a dozen series. An alternative is to estimate a dynamic moving average factor model, which can encompass richer sources of shocks and channels of transmission by accommodating a larger number of series. Hence, we also mention variance decomposition estimates from such a model, estimated for the U.S. and Canada on a similar sample. The reader is referred to an earlier version of this paper, Justiniano and Preston (2006), which builds on Justiniano (2007), for further details.

To explain a panel of 32 series (16 for each country) formal model comparisons dictate including four factors, two of which are common to both countries (foreign factors), with the remaining two exclusive to the Canadian economy (domestic). The factors and idiosyncratic, series-specific, components follow independent autoregressive processes of order three. Measures of fit also suggest the presence of moving average dynamics in the loadings, indicating that spillover effects may be important for some variables.

Justiniano and Preston (2006) show that the median share of the long-horizon variance

\footnotetext{
${ }^{6}$ The results obtained with this identification procedure are invariant to re-ordering of the series.
} 
of Canadian output, inflation, interest rates, the terms of trade and the real exchange rate explained by the two foreign factors is $0.71,0.15,0.31,0.22$ and 0.11 . While differences in sample and data preclude direct comparisons with the SUR results, this distinct methodology clearly indicates an important role for U.S. shocks in explaining Canadian business cycles, particularly for output. Similar findings are reported by Kose et al. (2003, 2008), Lumsdaine and Prasad (2003) and Bowden and Martin (1995) with related methodologies.

Taken together, these various statistics suggest strong comovement between Canadian and U.S. business cycles. The remainder of the paper explores whether structural models can similarly capture these international linkages.

\section{The Model}

Building on Gali and Monacelli (2005) and Monacelli (2005), the following section details a small open economy model, allowing for habit formation, indexation of prices, labor market imperfections and incomplete markets. These papers extend the microfoundations described by Clarida et al. (1999) and Woodford (2003) for analyzing monetary policy in a closed economy setting to an open economy context.

\subsection{Households}

Each household maximizes

$$
E_{0} \sum_{t=0}^{\infty} \beta^{t} \tilde{\varepsilon}_{g, t}\left[\frac{\left(C_{t}-H_{t}\right)^{1-1 / \sigma}}{1-1 / \sigma}-\frac{\tilde{\varepsilon}_{l, t} N_{t}^{1+\varphi}}{1+\varphi}\right]
$$

where $N_{t}$ is the labor input; $H_{t} \equiv h C_{t-1}$ is an external habit taken as exogenous by the household and $0<h<1 ; \sigma^{-1}, \varphi>0$ are the inverse elasticities of intertemporal substitution and labor supply; and $\tilde{\varepsilon}_{g, t}$ and $\tilde{\varepsilon}_{l, t}$ denote preference and labor supply shocks respectively. $C_{t}$ is a composite consumption index

$$
C_{t}=\left[(1-\tau)^{\frac{1}{\eta}}\left(C_{H, t}\right)^{\frac{\eta-1}{\eta}}+\tau^{\frac{1}{\eta}}\left(C_{F, t}\right)^{\frac{\eta-1}{\eta}}\right]^{\frac{\eta}{\eta-1}}
$$

where $C_{H, t}$ and $C_{F, t}$ are Dixit-Stiglitz aggregates of the available domestic and foreign produced goods given by

$$
C_{H, t}=\left[\int_{0}^{1} C_{H, t}(i)^{\frac{\theta-1}{\theta}} d i\right]^{\frac{\theta}{\theta-1}} \quad \text { and } \quad C_{F, t}=\left[\int_{0}^{1} C_{F, t}(i)^{\frac{\theta-1}{\theta}} d i\right]^{\frac{\theta}{\theta-1}}
$$


where $\eta>0$ gives the elasticity of substitution between domestic and foreign goods; $\theta>1$ is the elasticity of substitution between types of differentiated domestic or foreign goods; and $\tau$ the relative weight of these goods in the overall consumption bundle.

Assuming the only available assets are one-period domestic and foreign bonds, optimization occurs subject to the flow budget constraint

$$
P_{t} C_{t}+D_{t}+S_{t} B_{t}=D_{t-1} R_{t-1}+S_{t} B_{t-1} R_{t-1}^{*} \phi_{t}\left(A_{t}\right)+\Pi_{H, t}+\Pi_{F, t}+W_{t} N_{t}+T_{t}
$$

for all $t>0$, where $D_{t}$ and $B_{t}$ denote holdings of one-period domestic and foreign bonds with gross interest rates $R_{t}$ and $R_{t}^{*}$. $S_{t}$ is the nominal exchange rate. The price indices $P_{t}, P_{H, t}$ and $P_{t}^{*}$ correspond to the domestic CPI, domestic goods prices and foreign prices and are defined below. Households receive wages $W_{t}$ for labor supplied and $\Pi_{H, t}$ and $\Pi_{F, t}$ denote profits from equity holdings in domestic and retails firms. $T_{t}$ denotes taxes and transfers.

Following Benigno (2001), Kollmann (2002) and Schmitt-Grohe and Uribe (2003), the function $\phi_{t}(\cdot)$ is interpretable as a debt elastic interest rate premium given by

$$
\phi_{t}=\exp \left[-\chi\left(A_{t}+\tilde{\phi}_{t}\right)\right] \quad \text { where } \quad A_{t} \equiv \frac{S_{t-1} B_{t-1}}{\bar{C}_{F} P_{t-1}}
$$

is the real quantity of outstanding foreign debt expressed in terms of domestic currency as a fraction of steady state consumption of the imported good and $\tilde{\phi}_{t}$ a risk premium shock. This ensures stationarity of the foreign debt level in a log-linear approximation to the model.

Implicitly underwriting this expression for the budget constraint is the assumption that all households in the domestic economy receive an equal fraction of both domestic and retail firm profits and that labor income risk is pooled across agents. Absent this assumption, which imposes complete markets within the domestic economy, the analysis would require modeling the distribution of wealth across agents. This assumption also ensures that households face identical decision problems and choose identical state-contingent plans for consumption.

The household's optimization problem requires allocation of expenditures across all types of domestic and foreign goods both intratemporally and intertemporally. This yields the following set of optimality conditions. The demand for each category of consumption good is

$$
C_{H, t}(i)=\left(P_{H, t}(i) / P_{H, t}\right)^{-\theta} C_{H, t} \text { and } C_{F, t}(i)=\left(P_{F, t}(i) / P_{F, t}\right)^{-\theta} C_{F, t}
$$

for all $i$ with associated aggregate price indexes for the domestic and foreign consumption bundles given by $P_{H, t}$ and $P_{F, t}$. The optimal allocation of expenditure across domestic and 
foreign goods implies the demand functions

$$
C_{H, t}=(1-\tau)\left(P_{H, t} / P_{t}\right)^{-\eta} C_{t} \quad \text { and } \quad C_{F, t}=\tau\left(P_{F, t} / P_{t}\right)^{-\eta} C_{t}
$$

where $P_{t}=\left[(1-\tau) P_{H, t}^{1-\eta}+\tau P_{F, t}^{1-\eta}\right]^{\frac{1}{1-\eta}}$ is the consumer price index. Allocation of expenditures on the aggregate consumption bundle satisfies

$$
\lambda_{t}=\tilde{\varepsilon}_{g, t}\left(C_{t}-H_{t}\right)^{-1 / \sigma}
$$

and portfolio allocation is determined by the optimality conditions

$$
\begin{aligned}
\lambda_{t} S_{t} P_{t} & =\beta E_{t}\left[R_{t}^{*} \phi_{t+1} \lambda_{t+1} S_{t+1} P_{t+1}\right] \\
\lambda_{t} P_{t} & =\beta E_{t}\left[R_{t} \lambda_{t+1} P_{t+1}\right]
\end{aligned}
$$

for Lagrange multiplier $\lambda_{t}$. The latter when combined with (2) gives the Euler equation.

The household problem in the foreign economy is similarly described with the exceptions now noted. Because the foreign economy is approximately closed (the influence of the domestic economy is negligible), the available consumption bundle comprises the continuum of foreign produced goods $C_{F, t}^{*}(j)$ for $j \in[0,1]$. Foreign households need only decide how to allocate expenditures across these goods in any time period $t$ and also over time. Foreign debt in the foreign economy is in zero net supply, using the property that the domestic economy engages in negligible financial asset trade. There is no access to domestic debt markets for foreign agents. Conditions (2) and (4) continue to hold with all variables taking superscript "**".

\subsection{Optimal Labor Supply}

Following Erceg et al. (2000) and Woodford (2003, chap. 3), assume a single economy-wide labor market and that producers of the domestic good hire the same bundle of labor inputs at common wage rates. Firm $j$ produces good $j$ with technology $Y_{t}(j)=\tilde{\varepsilon}_{a, t} f\left(N_{t}(j)\right)$ where $\tilde{\varepsilon}_{a, t}$ is a neutral technology shock and $f(\cdot)$ satisfies the usual Inada conditions. The labor input used in the production of each good $j$ and associated aggregate wage index are given by the CES aggregators

$$
N_{t}(j) \equiv\left[\int_{0}^{1} N_{t}(k)^{\frac{\theta_{w}-1}{\theta_{w}}} d k\right]^{\frac{\theta_{w}}{\theta_{w}-1}} \text { and } W_{t}=\left[\int_{0}^{1} W_{t}(k)^{1-\theta_{w}} d k\right]^{\frac{1}{1-\theta_{w}}}
$$


for $\theta_{w}>1$. Firm $j$ 's demand for each type of labor $k$ is determined by maximizing the former index for a given level of wage payment. This gives the demand function

$$
N_{t}(k)=N_{t}(j)\left(\frac{W_{t}(k)}{W_{t}}\right)^{-\theta_{w}}
$$

Households supply their labor under monopolistic competition. They face a Calvo-style wage-setting problem, having the opportunity to re-optimize their wage with probability $1-\alpha_{w}$ each period, where $0<\alpha_{w}<1$. As in Christiano et al. (2005) and Woodford (2003, chap. 3), households not re-optimizing adjust their wage according to the indexation rule

$$
\log W_{t}(k)=\log W_{t-1}(k)+\gamma_{w} \pi_{t-1}
$$

where $0 \leq \gamma_{w} \leq 1$ measures the degree of indexation to the previous-period's inflation rate and $\pi_{t}=\log \left(P_{t} / P_{t-1}\right)$. Since all households having the opportunity to reset their wage face the same decision problem, they set a common wage, $W_{t}$.

The household's wage-setting problem in period $t$ is to maximize

$$
E_{t} \sum_{T=t}^{\infty}\left(\alpha_{w} \beta\right)^{T-t}\left[\lambda_{T} W_{t}(k)\left(\frac{P_{T-1}}{P_{t-1}}\right)^{\gamma_{w}} N_{T}(k)-\frac{\tilde{\varepsilon}_{l, t} N_{T}(k)^{1+\varphi}}{1+\varphi}\right]
$$

by choice of $W_{t}(k)$ subject to the labor demand function (5). The first-order condition for this problem is

$$
E_{t} \sum_{T=t}^{\infty}\left(\alpha_{w} \beta\right)^{T-t}\left[\lambda_{T}\left(\frac{P_{T-1}}{P_{t-1}}\right)^{\gamma_{w}}\left(N_{T}(k)+W_{t}(k) \frac{\partial N_{T}(k)}{\partial W_{t}(k)}\right)-\tilde{\varepsilon}_{l, t} N_{T}^{\varphi} \frac{\partial N_{T}(k)}{\partial W_{t}(k)}\right]=0 .
$$

Households in the foreign block face an identical problem, with appropriate substitution of foreign variables and technology and preference parameters.

\subsection{Domestic Producers}

There is a continuum of monopolistically competitive domestic firms producing differentiated goods. Calvo-style price setting is assumed, allowing for indexation to past domestic goodsprice inflation. In any period $t$, a fraction $1-\alpha_{H}$ of firms set prices optimally, while a fraction $0<\alpha_{H}<1$ of goods prices are adjusted according to the indexation rule

$$
\log P_{H, t}(i)=\log P_{H, t-1}(i)+\gamma_{H} \pi_{H, t-1},
$$

where $0 \leq \gamma_{H} \leq 1$ measures the degree of indexation to the previous-period's inflation rate and $\pi_{H, t}=\log \left(P_{H, t} / P_{H, t-1}\right)$. Since all firms having the opportunity to reset their price in 
period $t$ face the same decision problem, they set a common price $P_{H, t}^{\prime}$. Firms setting prices in period $t$ face a demand curve

$$
y_{H, T}(i)=\left(\frac{P_{H, t}(i)}{P_{H, T}} \cdot\left(\frac{P_{H, T-1}}{P_{H, t-1}}\right)^{\gamma_{H}}\right)^{-\theta}\left(C_{H, T}+C_{H, T}^{*}\right)
$$

for all $t$ and take aggregate prices and consumption bundles as parametric.

The firm's price-setting problem in period $t$ is to maximize the expected present discounted value of profits

$$
E_{t} \sum_{T=t}^{\infty} \alpha_{H}^{T-t} Q_{t, T}\left[P_{H, t}(i)\left(\frac{P_{H, T-1}}{P_{H, t-1}}\right)^{\gamma_{H}} y_{H, T}(i)-W_{T} f^{-1}\left(\frac{y_{H, T}(i)}{\tilde{\varepsilon}_{a, t}}\right)\right]
$$

subject to the demand curve (8), where $Q_{t, T}$ is interpreted as a stochastic discount factor evaluated at aggregate income. This implies the first-order condition

$$
E_{t} \sum_{T=t}^{\infty} \alpha_{H}^{T-t} Q_{t, T} y_{H, T}(i)\left[P_{H, t}(i)\left(\frac{P_{H, T-1}}{P_{H, t-1}}\right)^{\gamma_{H}}-\frac{\theta}{\theta-1} P_{H, T} M C_{T}\right]=0
$$

where $M C_{t}$ is the marginal cost function of firm $i$.

Foreign firms face an analogous problem. Thus the optimality condition takes an identical form, with all variables taking the superscript "** and the subscript $H$ being changed to $F$. Preferences and shocks are allowed to differ and the small open economy assumption implies that $P_{t}^{*}$ is equivalent to $P_{F, t}^{*}$.

\subsection{Retail Firms}

Retail firms in the small open economy import foreign differentiated goods for which the law of one price holds at the docks. In determining the domestic currency price of imported goods they are monopolistically competitive. Pricing power leads to a violation of the law of one price in the short run.

Like domestic firms, retail firms face a Calvo-style price-setting problem allowing for indexation to past inflation. A fraction $1-\alpha_{F}$ of firms set prices optimally, while a fraction $0<\alpha_{F}<1$ of goods prices are adjusted according to an indexation rule analogous to (7) with indexation parameter $0<\gamma_{F}<1$. Firms setting prices in period $t$ face a demand curve

$$
C_{F, T}(i)=\left(\frac{P_{F, t}(i)}{P_{F, T}} \cdot\left(\frac{P_{F, T-1}}{P_{F, t-1}}\right)^{\gamma_{F}}\right)^{-\theta} C_{F, T}
$$


and take aggregate prices and consumption bundles as parametric. The firm's price-setting problem in period $t$ is to maximize the expected present discounted value of profits

$$
E_{t} \sum_{T=t}^{\infty} \alpha_{F}^{T-t} Q_{t, T} C_{F, T}(i)\left[P_{F, t}(i)\left(\frac{P_{F, T-1}}{P_{F, t-1}}\right)^{\gamma_{F}}-S_{T} P_{F, T}^{*}(i)\right]
$$

subject to the demand curve, (10), and implies the first-order condition

$$
E_{t} \sum_{T=t}^{\infty} \alpha_{F}^{T-t} Q_{t, T}\left[P_{F, t}(i)\left(\frac{P_{F, T-1}}{P_{F, t-1}}\right)^{\gamma_{F}}-\frac{\theta}{\theta-1} S_{T} P_{H, T}^{*}(i)\right]=0 .
$$

In the foreign economy there is no analogous optimal pricing problem. Because imports form a negligible part of the foreign consumption bundle, variations in the import price have a negligible effect on the evolution of the foreign price index, $P_{t}^{*}$, and need not be analyzed.

\subsection{International Risk Sharing and Prices}

Optimality conditions for domestic and foreign bond holdings imply the uncovered interest rate parity condition

$$
E_{t} \lambda_{t+1} P_{t+1}\left[R_{t}-R_{t}^{*}\left(S_{t+1} / S_{t}\right) \phi_{t+1}\right]=0
$$

placing a restriction on the relative movements of domestic and foreign interest rates, and changes in the nominal exchange rate.

The terms of trade is defined as $P_{F, t} / P_{H, t}$. The real exchange rate is given by $S_{t} P_{t}^{*} / P_{t}$. Since $P_{t}^{*}=P_{F, t}^{*}$, when the law of one price fails to hold $\tilde{\Psi}_{F, t} \equiv S_{t} P_{t}^{*} / P_{F, t} \neq 1$, which defines what Monacelli (2005) calls the law of one price gap. The models of Gali and Monacelli (2005) and Monacelli (2005) are respectively characterized by whether or not $\tilde{\Psi}_{F, t}=1$.

\subsection{Monetary and Fiscal Policy}

Monetary policy is conducted according to a Taylor-type rule

$$
\frac{R_{t}}{\bar{R}}=\left(\frac{R_{t-1}}{\bar{R}}\right)^{\rho_{i}}\left[\left(\frac{P_{t}}{P_{t-1}}\right)^{\phi_{\pi}}\left(\frac{Y_{t}}{\bar{Y}}\right)^{\phi_{y}}\left(\frac{Y_{t}}{Y_{t-1}}\right)^{\phi_{\Delta y}}\left(\frac{S_{t}}{S_{t-1}}\right)^{\phi_{S}}\right]^{\left(1-\rho_{i}\right)} \tilde{\varepsilon}_{m, t}
$$

where $\bar{R}$ and $\bar{Y}$ are steady state values of gross nominal interest rates and output and $\tilde{\varepsilon}_{m, t}$ is an exogenous disturbance. Policy responds to contemporaneous values of inflation, output, output growth and the growth rate in the nominal exchange rate. Evidence for rules that respond to exchange rates in various small open economies is found in Lubik and Schorfheide (2005b). Fiscal policy is specified as a zero debt policy. 


\subsection{Exogenous Disturbances}

All shocks have unit means. In log deviations from steady the following assumptions are made. In the foreign block, the technology, preference and labor disutility shocks are firstorder autoregressive processes. The monetary policy innovation is i.i.d. In the domestic block, technology, preference and labor disutility shocks are first-order autoregressive processes. The monetary policy shock is i.i.d. Finally, the risk premium shock is a first-order autoregressive process. In estimation we allow for additive disturbances in the Phillips curves for foreign goods-price inflation, domestic goods-price inflation and imported goods-price inflation. The former two are i.i.d. processes, while the latter is a first-order autoregressive process. These shocks can be interpreted as exogenous variation in firm mark-ups.

\subsection{General Equilibrium}

Equilibrium requires that all markets clear. Goods market clearing requires

$$
Y_{H, t}=C_{H, t}+C_{H, t}^{*} \text { and } Y_{t}^{*}=C_{t}^{*}
$$

in the domestic and foreign economies respectively. The model is closed assuming foreign demand for the domestically produced good is specified as

$$
C_{H, t}^{*}=\left(\frac{P_{H, t}^{*}}{P^{*}}\right)^{-\lambda} Y_{t}^{*}
$$

where $\lambda>0$. This demand function is standard in small open economy models (see Kollmann (2002) and McCallum and Nelson (2000)) and nests the specification in Monacelli (2005) by allowing $\lambda$ to be different from $\eta$, the domestic elasticity of substitution across goods in the domestic economy, to give additional flexibility in the transmission mechanism of foreign disturbances to the domestic economy. Our results are unaffected by the parametrization of this demand function. ${ }^{7}$ The dynamics of $Y_{t}^{*}$ and other foreign variables remain specified by the structural relations developed above. Domestic debt is in zero net supply so that $D_{t}=0$ for all $t .^{8}$

The analysis considers a symmetric equilibrium in which all domestic producers setting prices in period $t$ set a common price $P_{H, t}$. Similarly, all domestic retailers and foreign firms

\footnotetext{
${ }^{7}$ Constraining $\lambda$ to equal $\eta$ results in identical insights from the estimation, and, therefore, we report results based on this more general specification.

${ }^{8} \mathrm{~A}$ similar condition holds for the foreign economy once it is noted that domestic holdings of foreign debt, $B_{t}$, is negligible relative to the size of the foreign economy.
} 
each choose a common price $P_{F, t}$ and $P_{t}^{*}$. Analogous conditions hold for wage setters in the domestic and foreign economies. Finally, we assume households have identical initial wealth, so that each faces the same period budget constraint and make identical consumption and portfolio decisions.

\section{Estimation Methodology and Data}

\subsection{Estimation and Priors}

Model parameters are estimated using Bayesian methods now used extensively in the empirical macroeconomics literature - see Schorfheide (2000) for a seminal reference and Justiniano and Preston (2006) for further details in the context of the model estimated here. We work with a log-linear approximation of the model in a neighborhood of a non-stochastic steady state. ${ }^{9}$ The observables used in estimation were described in section 2.

The first column of table 2 presents the priors for the coefficients, indicating the density, median and standard deviation. They are motivated by earlier work, are fairly uncontroversial, and accord with other studies adopting Bayesian inference. Several parameters, not well identified, are calibrated. The discount factor is fixed at 0.99. The elasticities of demand across varieties of goods and labor inputs in both the domestic and foreign block are set equal to 8, as in Woodford (2003). Following Benigno (2001), the parameter governing the interest rate elasticity of debt is fixed at $0.01 .^{10}$

Priors that are particularly germane to the transmission of foreign shocks deserve further comment. The densities for the degree of openness, $\tau$, and the the elasticity of substitution between home and foreign goods, $\eta$, are chosen to generate a tight distribution for the steady state share of imports to GDP, centered at 0.27 as in the data. ${ }^{11}$ For $\tau$ we specify a beta density with mean 0.29 , matching the average trade share in our sample, and a tight standard deviation of 0.1 . For $\eta$ we choose a normal with mean 0.9 and also small dispersion of 0.1 . Our results are even stronger with looser priors on $\tau$, which produce implausibly low estimates. ${ }^{12}$

For the exogenous shocks, priors are guided both by closed economy estimates of similar

\footnotetext{
${ }^{9}$ Details of these calculations are available on request.

${ }^{10}$ In the working paper version we evidenced the robustness of our results to alternative calibrations with the elasticities of demand equal to 4 or when setting the interest elasticity of interest rate debt to $1 \mathrm{e}-4$.

${ }^{11}$ We are grateful to one of the referees for this suggestion.

${ }^{12}$ None of our results are affected when actually calibrating $\tau$ at 0.29 .
} 
disturbances for the U.S. and consistency of the implied degree of volatility and persistence with the corresponding observables in each country. Our baseline specification also includes a "tilt" towards foreign block disturbances, which are assumed twice as volatile and more persistent than their domestic counterparts.

To jointly evaluate the economic content of these priors, table 3 presents their implications for the variance share of the domestic observable variables attributed to foreign disturbances. This analysis is more useful than commenting on specific priors and at the heart of our analysis. "Foreign" denotes shocks originating in the U.S. block, as only these disturbances can potentially explain comovement. Risk-premium and import cost-push shocks could be labelled as "open economy" disturbances, but would not account for the correlation with U.S. series. The prior specification permits a substantial role for U.S. shocks in driving Canadian fluctuations and comovement readily obtains with plausible calibrations of the model. ${ }^{13}$ Moreover, the $[5,95]$ prior probability bands indicate that this specification can in principle easily replicate the variance shares reported with the SUR.

\subsection{Estimates and Model Fit}

Table 2 reports parameter estimates for the baseline model, determined after extensive investigation of alternative specifications. ${ }^{14}$ These included various combinations of endogenous and exogenous persistence mechanisms, and alternative combinations of shocks, e.g. cost-push shocks in price setting of all three markets or correlated technology shocks. The robustness of our results to alternative specifications is addressed later.

Parameter estimates are reasonable. The degree of price stickiness in the production of home produced goods, both in the domestic and foreign blocks of the model, is high. However, estimates for the foreign block agree with Levin et al. (2005). Note that cost-push shocks to the domestic and foreign Phillips' curve are white noise and we do not rely on a time-varying inflation target to impart inflationary inertia. The Calvo adjustment parameters for wages in the domestic and foreign economies are similar to those reported in Del Negro et al. (2007)

\footnotetext{
${ }^{13}$ The variance decomposition at the prior means is almost identical to the means in table 3 for output, hours and the terms of trade, while $10 \%$ larger for inflation and interest rates, but smaller for wages by a similar amount.

${ }^{14}$ We initialize multiple chains using random starting values after launching 50 optimization runs to ensure they all converge to the same mode. Convergence of the MCMC chains is diagnosed looking at trace plots and the potential scale reduction factors for variances and $90 \%$ posterior bands.
} 
on a longer sample for the U.S. Imported goods prices are re-optimized most frequently, every 2 quarters.

The degree of habit persistence is close to 0.6 in both countries, tightly estimated and in line with values in Boldrin et al. (2001). The intertemporal elasticity of substitution and elasticity of labor supply accord with earlier macroeconomic studies of this kind. The estimated coefficients of the Taylor rule align with conventional wisdom. Technology and preference shocks are highly persistent in both countries. This is also true of risk premium and imported goods cost-push shocks in Canada. The median estimate for the elasticity of substitution across home and foreign goods is 0.86 , below the value of 1.5 used in calibrations by Chari et al. (2002) and Schmitt-Grohe (1998), but consistent with estimates in Gust et al. (2008). Finally, the posterior density for the degree of openness lies well in the left tail of our very tight prior.

In Justiniano and Preston (2006) we show that the model matches the volatility and persistence of the data within blocks. ${ }^{15}$ The rest of the paper is devoted to the model's performance across blocks.

\section{Accounting for the Influence of Foreign Shocks}

This section documents the central result of the paper: the baseline model with independent shocks is unable to account for the transmission of foreign disturbances and international comovement. Two pieces of evidence are adduced. First, variance decompositions reveal that U.S. disturbances explain a negligible fraction of variation in the domestic economy. Second, model-implied bivariate correlations between foreign and domestic series are very close to zero. Both findings are clearly at odds with the reduced-form evidence discussed in section 2 .

\subsection{Variance Decompositions in the DSGE model}

Using the draws from the posterior density of model parameters, Table 4 reports the posterior variance shares in the domestic series - including the real exchange rate and terms of trade — that is attributable to all five foreign disturbances, at several forecast horizons. We report medians and 90 percent posterior probability bands.

\footnotetext{
${ }^{15}$ This is also evident from the unreported cross-correlation functions within each block.
} 
Regardless of forecast horizon, virtually none of the observed variation in domestic series is attributable to foreign disturbances. For output, interest rates, inflation, hours and wages, their maximum contribution at a horizon of 1 quarter is 3 percent. At longer horizons U.S. shocks explain at most 1 percent. Furthermore, the 95 percentiles for the variance shares of these series never exceeds 4 percent. For the real exchange rate and terms of trade, these statistics reveal a slightly larger contribution of foreign shocks, but never greater than 7 percent. Compared with the reduced-form evidence in table 1, it is clear that this specification of the model cannot account for the influence of foreign shocks.

\subsection{Cross-Country Correlations in the DSGE Model}

Section 2 discussed the empirical cross-correlations between Canadian and U.S. series shown in figure 1 (black). Here we revisit that figure focusing on the moments implied by the estimated model. These statistics are computed by taking draws from the posterior distribution of the DSGE parameters and simulating artificial samples of length equal to the data. We report median (grey) and [5,95] percent posterior probability bands (dashed).

The median model-implied cross-correlations are virtually zero at all horizons. An immediate consequence is that the DSGE model cannot replicate the common fluctuations of domestic series with U.S. variables. For many Canadian series, the data cross-correlations lie outside the (wide) posterior probability bands of the corresponding model statistics. This is evident in the cross-correlations between Canadian output, nominal interest rates and wages and their U.S. counterparts. Similarly the contemporaneous correlation between inflation in the two countries is poorly fit. In general, many of the remaining cross-correlations are not well matched. Even for moments where the posterior bands encompass the data, it is rarely true (except for hours) that the data correlation is close to zero. This mismatch between model and data is far less evident for the real exchange rate and the terms of trade (not shown for space considerations).

Recall that the lack of meaningful effects from foreign shocks in the domestic series is not an inherent feature of the DSGE model (compare tables 3 and 4). Moreover, the inability to explain the influence of foreign disturbances is not unique to the estimated model of this paper. Adolfson et al. (2005) estimate a richer model which fits the data very well in several dimensions but also reveals, for Sweden, negligible variance shares for shocks originating in 
the rest of the world. While the authors do not comment on this issue, their estimated model includes features such as a stochastic trend, investment, variable capital utilization and a working capital channel, whose absence here could have been suspected as culprit for our results. Similarly, de Walque et al. (2005) fail to identify significant cross-country linkages in an estimated two-country model for the U.S. and the Euro area, suggesting that the small open economy assumption is not responsible for our findings either.

\section{Robustness}

The benchmark specification makes a range of assumptions, both on model structure and its match with data. Table 5 presents the estimated contribution of foreign disturbances to the variability of Canadian series for a number of alternative specifications. A larger set of robustness checks is conducted in Justiniano and Preston (2006). To present a worst-case scenario against our findings, the numbers reported are for the horizon at which the share for output is greatest. A comparison with the first column, which replicates our baseline specification, makes clear that our central result remains intact.

Column 2 presents the decomposition when the prior standard deviations of all shocks are uniform between 1e-4 and 10. Compared with the benchmark results there is clearly little difference in the variance decompositions. The next two columns evaluate the sensitivity of our conclusions to the choice of observables used to confront the model with data. Column 3 reports shares when output and wages are in first differences rather than in level deviations from a common trend. The results are unchanged. Column 4 includes the observed terms of trade and the real exchange rate in levels rather than differences. This matters little for the contribution of U.S. shocks in Canada, except for a somewhat larger share for the terms of trade and real exchange rate.

Coordinated policy responses could perhaps explain part of the comovement in Canadian and U.S. business cycles. In the baseline specification monetary policies are assumed to be independently determined. However, interest rate decisions in Canada might be influenced by changes in U.S. interest rates beyond what can be accounted for with an explicit response to the exchange rate. Given the estimated degree of price stickiness, explicitly including a link between U.S. and Canadian monetary policy decisions may better capture international comovement. In this spirit, a log-linearized alternative specification for Canadian monetary 
policy is

$$
i_{t}=\rho_{i} i_{t-1}+\left(1-\rho_{i}\right)\left[\phi_{i^{*}} i_{t-1}^{*}+\phi_{\pi} \pi_{t}+\phi_{y} y_{t}+\phi_{\Delta y} \Delta y_{t}\right]+\varepsilon_{m, t}
$$

where there is now an explicit dependence on lagged realizations of U.S. interest rates. All remaining modeling equations are unchanged. ${ }^{16}$ With a posterior mode estimate for $\phi_{i^{*}}$ of 0.04, it is not surprising that the variance decompositions are largely unchanged (last column). Identical conclusions obtain even when policy responds to contemporaneous U.S. interest rates.

\section{Common Shocks}

The benchmark model assumes that all shocks in the U.S. and Canada are independent. However, the empirical evidence presented in section 2 is consistent with both spillovers from U.S. specific disturbances and the existence of common shocks affecting both countries. This section presents alternative model specifications that accommodate the latter. Such specifications are unusual in the new open economy macroeconomics literature. Notable exceptions are Adolfson et al. (2007) and de Walque et al. (2005) which include a common stochastic trend in neutral technology.

\subsection{Specification}

Common shocks are introduced by expressing the Canadian disturbances in the model as the sum of two orthogonal shocks. The first one is shared with the same disturbance in the U.S. block and referred to as the common shock. The second component affects only the domestic block and is labelled a country-specific shock. There is still no spillover from the Canadian to the U.S. economy given the small open economy assumption.

As an illustration, when modeling a common shock in aggregate neutral technology this disturbance in Canada is written as $a_{t}=a_{t}^{*}+a_{t}^{d}$ where the common shock, $a_{t}^{*}$, and countryspecific shock, $a_{t}^{d}$, evolve as independent $\operatorname{AR}(1)$ processes. The common shock is the corresponding structural disturbance in the U.S. block. Its share of variability in Canadian neutral technology, $\operatorname{Var}\left(a^{*}\right) / \operatorname{Var}(a)$, and implied correlation, $\operatorname{corr}\left(a, a^{*}\right)$, can be readily computed.

In this way, common components are introduced between Canadian disturbances to preferences, labor disutility, home-goods inflation and monetary policy, and their respective counterparts in the U.S. This can be viewed as a DSGE structural approximation to the decomposition

\footnotetext{
${ }^{16}$ The prior for $\phi_{i^{*}}$ is normal with mean 0.3 and dispersion 0.2 , allowing it to take negative values.
} 
into common and idiosyncratic components using reduced-form dynamic factor models, as in Kose et al. (2003, 2008). An advantage of this specification relative to the direct estimation of the correlations, $\operatorname{corr}\left(a, a^{*}\right)$, is that it allows for a clean decomposition of the variance of all series attributed to each component.

Given the emphasis on technology shocks in the international RBC literature, a natural starting point for adding common shocks would have been to introduce a common unit root in neutral technology. A difficulty with this approach is strong evidence against a common stochastic trend in U.S. and Canadian output, at least in our sample. Tests for cointegration between log output per-capita in both countries do not reject the null hypothesis of no cointegration, regardless of the specification of lags and deterministic components. ${ }^{17}$ Similarly, the null of a unit root in the difference in levels of these two series cannot be rejected, while the null of stationarity is rejected. ${ }^{18}$ These results accord well with a persistent gap in labor productivity across these two countries; a topic that has been the subject of substantial research and policy discussion in Canada - see Eldridge and Sherwood (2001) and references therein. ${ }^{19}$

\subsection{Posterior variance shares with common shocks}

For each U.S. shock and Canadian counterpart we re-estimate the model when common components are initially introduced one at a time. This permits identifying which common disturbances can account for the comovement in the data. A specification with a common component in all shocks is also presented.

Priors are as in the baseline model with one exception. For both common and countryspecific shocks we specify the same density: a $B(0.6,2)$ for the autoregressive coefficients, and an $I G$ for their standard deviations equal to that of the corresponding U.S. shock in table 1.

\footnotetext{
${ }^{17}$ We use both the trace and maximum eigenvalue tests, allowing for 1-6 lags while also varying the presence/absence of an intercept in the VAR or the cointegrating relationship. That is, we searched over 24 possible specifications while gauging their relative fit using both the BIC and AIC. For each lag length, both information criteria prefer a specification with an intercept in the VAR and cointegrating equation (as expected) in which case the null of no cointegration cannot be rejected with either test (for all lags considered). The p-values for the null of no cointegration are never below 0.2 and close to 0.5 if the preferred lag lengths are used.

${ }^{18}$ The null of a unit root is not rejected at the 10 percent significance level when using the test of Elliot et al. (1996) or any of the test statistics proposed by Ng and Perron (2001), both with automatic lag selection. The null of stationarity under the KPSS tests is rejected at the 5 percent level.

${ }^{19}$ Labor productivity is an observed state in our model since we are using data on output and hours for each country. The filtered series matches labor productivity from Statistics Canada (Table 383-0012).
} 
Common and country-specific disturbances are on equal footing. ${ }^{20}$ Relative to table 3 , this further increases the prior variance share explained by the sum of all U.S. shocks, which now includes the fraction attributed to the common components. Results would be very similar using the prior from the baseline specification. ${ }^{21}$

Panel A in table 6 reports posterior variance shares for specifications with a single common shock. We report the horizon with the largest share for output. Comparing these results with the baseline variance decomposition, yields several interesting findings.

Introducing a common component in neutral technology alone does little to alter the contribution of U.S. shocks, except for hours (column 1). Spillovers in neutral technology here play a small role in reproducing comovement. The intuition for this finding is that in our model neutral technology shocks induce a negative comovement between output and hours, as documented in closed economy models by Gali (1999), Ireland (2004) and Gali and Rabanal (2004). However, as noted by Rios-Rull et. al. (2007) the generality of this result across methodologies is still a matter of debate in closed economies.

A common shock to the disutility of labor only (column 2) has a negligible effect on the variance decomposition of output, inflation and interest rates, but helps improve the foreign share in wages. Cost-push shocks (column 3) similarly have small effects, though assist in bumping up the foreign contribution to inflation variability.

With a common shock only in the monetary policy rules (column 4), the fraction of the variance in Canadian interest rate and output attributable to foreign shocks climbs to 23 and 10 percent, respectively. The largest increase in the share of output variability explained by U.S. disturbances occurs with a common component in preference shocks (column 5), but even in this case only 11 percent of output fluctuations are accounted for by all foreign shocks.

Panel B reports shares at various horizons in a specification with common components in all U.S. shocks and their respective Canadian counterparts. The fraction of variability attributed to all foreign disturbances is now larger than in the baseline, particularly for output and

\footnotetext{
${ }^{20}$ The implied prior distribution of the correlation coefficient between the (aggregate) Canadian disturbance and its common component, is quite dispersed with a mean and median of roughly 0.7 , standard deviation of 0.23 and $5-95 \%$ bands covering 0.08 to 0.99 . This is also the prior correlation with the country-specific part of the shock, e.g. $\operatorname{corr}\left(a, a^{d}\right)$. By construction the sum of these two squared correlations equals 1.

${ }^{21}$ In this case with the tilt towards the foreign block, the mean and median prior variance shares of the U.S. shocks would have jumped to $90 \%$ or above. Also, for each composite disturbance the median prior correlation with its common component would have been tightly centered around 0.95 . Nonetheless, the variance shares are only 1 to 3 percentage points higher with this alternative, extreme prior.
} 
interest rates. These results show that the comovement observed in the data can be partly reproduced by correlating domestic disturbances with all U.S. shocks.

There are at least three reasons why this last specification should not be viewed as panacea for the model's failure in accounting for the influence of foreign shocks. First and foremost, while shares in panel B align well with those from the SUR (table 2) at a 1 quarter horizon, for longer horizons the SUR posterior bands do not encompass the smaller DSGE estimates. Second, some of the common components are hard to rationalize on structural grounds. Recall that neither a specification of the Canadian policy rule including a direct response to the exchange rate nor to U.S. interest rates could explain comovement, unless shocks are correlated. This suggests that cross-equation restrictions prevent the model from structurally explaining the cross-correlation in these two series. Third, panel B demonstrates an extreme manifestation of the exchange rate disconnect analyzed by Devereux and Engel (2002). Fluctuations in the real exchange rate and the terms of trade are completely disconnected from the U.S. block and only somewhat less so from the real domestic variables. ${ }^{22}$ In summary, even with common shocks there is ample scope to improve the model's ability to capture the contribution of foreign shocks.

\section{Conclusion}

This paper shows that an empirical new open economy model fails to account for one important dimension of Canadian data: the influence of U.S. disturbances. We initially assume uncorrelated shocks across countries, as it is done in almost all the empirical literature with this class of models. Variance decompositions reveal that the fraction of variation in Canadian series attributed to all shocks originating in the U.S. economy is negligible at all forecast horizons. Accordingly, the cross-country correlation functions implied by the model are close to zero. These findings contrast sharply with earlier work documenting strong linkages between these two countries and reduced-form evidence presented here.

Alternative specifications with common shocks can only partially resolve this problem. A model in which all U.S. shocks have a common component with the corresponding Canadian

\footnotetext{
${ }^{22}$ Risk-premium and import cost-push shocks account for roughly 90 and 85 percent of the variance of the real exchange rate and the terms of trade, respectively, at all horizons, while explaining only about 5 percent of the variability in domestic output, real wages and hours.
} 
disturbances begins to reconcile the influence of foreign shocks in the model and the data. However, the variance shares explained by all U.S. shocks still fall short of those observed in the data at medium and long horizons. While the empirical evidence is consistent with both common shocks and spillovers, there remains the question of what economic effects do these common shocks capture in the model. In particular, whether they correspond to purely exogenous disturbances or are instead simply capturing model misspecification. Finally, any gains with common shocks come at the expense of fully detaching fluctuations in the exchange rate and the terms of trade from the foreign block.

Overall our findings suggest that additional work on the international transmission mechanisms of various shocks could improve the empirical performance of these models in this crucial dimension. An interesting exercise in this vein would be to alter the supply side of the model to account for cross-country linkages at multiple stages of production as in Huang and Liu (2007) and Burstein et al. (2008). Alternatively, expanding on international financial linkages and the role of asset prices will likely help explain the importance of U.S. disturbances abroad, as made evident by the current financial crisis.

\section{Appendix A: Data}

All series are downloaded from Haver Analytics. For the U.S., real per-capita GDP measures output, inflation corresponds to the log-difference in the GDP deflator, and the effective federal funds rate taken for interest rates. Nominal compensation per hour in the non-farm business sector divided by the GDP deflator measures wages. Total hours in the non-farm business sector is divided by population.

For Canada, real per-capita GDP is constructed with data from Statistics Canada (StatCan). The quarterly log difference in the consumer price index excluding food and energy (StatCan) measures overall inflation. The official discount rate published by the Bank of Canada corresponds to interest rates. Hours worked in the total economy (StatCan table 383-0012) is divided by population. From the same table we obtain total compensation and convert it into real terms. In accordance with the model, the GDP deflator proxies for the price of home produced goods, while CPI inflation represents the aggregate price index.

For consistency, the log difference in the bilateral real exchange rate is constructed as the sum the log growth rates in the U.S. GDP deflator and the nominal exchange rate (Canadian 
dollars per U.S. dollars) minus Canadian aggregate inflation, as measured above. An earlier version of the paper used the bilateral real exchange rate constructed by the IMF with identical findings.

Finally, for the terms of trade we take the ratio of the deflator for imports to exports (Statcan) matching in our model, $\log \left(P_{F, t} / P_{H, t}\right)$. According to Canada's national accounts data, this measure of the terms of trade would correspond more closely to $\log \left(P_{F, t}^{*} S_{t} / P_{H, t}\right)$, but this would not be consistent with the real exchange rate using aggregate U.S. inflation. As there is no perfect match between model variables we adopted the former measure for estimation. Inference with the latter interpretation does not affect our results.

\section{Appendix B: SUR model}

To match the reduced-form representation of the DSGE model we impose on a VAR the same zero restrictions of no feedback from Canada to the U.S. The resulting SUR model is estimated on the same sample of twelve series used for inference with the DSGE model.

Inference is substantially more involved than with a standard VAR, as the explanatory variables are not the same across all series. However, the estimation is feasible with the efficient block-recursive Gibbs algorithm proposed by Zha (1999), who documents the distortions to inference from not imposing the exclusion restrictions in a SUR between Canada and the U.S.

We simply outline the model and refer the readers to Zha (1999) for details. Partitioning the vector of observables $y_{t}$ into U.S. and Canadian variables, $y_{t}^{U S}$ and $y_{t}^{C N}$, respectively, the two blocks of the SUR are given by

$$
\left[\begin{array}{cc}
A_{U S, U S}(0)-A_{U S, U S}^{p}(L) & 0 \\
A_{C N, U S}(0)-A_{C N, U S}^{p}(L) & A_{C N, C N}(0)-A_{C N, U S}^{p}(L)
\end{array}\right]\left(\begin{array}{c}
y_{t}^{U S} \\
y_{t}^{C N}
\end{array}\right)=\left(\begin{array}{c}
\epsilon_{t}^{U S} \\
\epsilon_{t}^{C N}
\end{array}\right)
$$

for matrices of conformable size, where $A_{i, j}(0)$ corresponds to the impact matrix and $A_{i, j}^{p}(L)$ denotes a matrix of lag-polynomials, of order $p$, in the positive powers of $L$. The structural errors $\left[\epsilon_{t}^{\prime U S}, \epsilon_{t}^{\prime C N}\right]^{\prime}$ are orthogonal with unit variance.

Our goal is not to identify each of the structural disturbances but simply to compute the variance shares of the Canadian series attributed to the sum of all U.S. disturbances, $\epsilon_{t}^{U S}$. To this end, we impose a lower triangular structure in the impact matrices $A_{U S, U S}(0)$ and $A_{C N, C N}(0)$. This is equivalent to a Cholesky decomposition of the reduced-form SUR covariance matrix. Results on the sum of all block-specific disturbances are invariant to ordering. 
We report results with $p=4$ in light of recent work by Fernandez-Villaverde et al. (2007) and Del Negro et al. (2007) who have brought attention to the issue of lag truncation in VARs as approximations to DSGE models. To deal with the large number of parameters relative to sample length, we use priors that shrink coefficients at distant lags. More specifically, we specify the priors $A_{i j}(1) \sim N(0.9,0.2)$ for $i=j$ and $N(0,0.4)$ for $i \neq j .{ }^{23}$ There's no distinction between own and others' lags for $k>1$ and assume a normal prior centered at zero with a dispersion equal to 0.2 for $k=2,0.15$ for $k=3$, and 0.1 for $k=4$. The lower triangular elements of the contemporaneous matrices are $A_{i j}(0) \sim N(0,10)$. Results are largely insensitive to looser priors, and, when feasible ( $p$ is 1 or 2 ), pretty much identical to sampling a single block SUR with an uninformative Inverse-Wishart prior on the reduced-form covariance matrix.

The Gibbs sampler is initialized at random starting values from the prior (or a classical SUR with 2 lags) and we run 3 chains, discarding, for each, the first 40,000 draws, and retaining 1 in 10 of the remaining 50000. For each draw we compute the fraction of the variability in $y_{t}^{C N}$, explained by the sum of all five U.S. shocks, at different horizons.

\section{References}

Adolfson, M., S. Laseen, J. Linde, and M. Villani (2005): "Bayesian Estimation of an Open Economy DSGE Model with Incomplete Pass-Through," Working Paper Series 179, Sveriges Riksbank.

(2007): "Bayesian Estimation of an Open Economy DSGE Model with Incomplete Pass-Through," Journal of International Economics, 72(2), 481-511.

Ambler, S., E. Cardia, and C. Zimmerman (2004): "International Business Cycles: What are the Facts?," Journal of Monetary Economics, (51), 257-276.

Backus, D. K., and P. J. Kenoe (1992): "International Evidence on the Historical Properties of Business Cycles," American Economic Review, 82, 864-888.

Backus, D. K., P. J. Kehoe, and F. E. Kydland (1992): "International Real Business Cycles," Journal of Political Economy, 100, 745-773.

- (1995): "Internation Business Cycles: Theory and Evidence," in Frontiers of Business Cycle Research, ed. by T. F. Cooley, pp. 331-356.

Baxter, M. (1995): "International Trade and Business Cycles," in Handbook of Internation Economics, ed. by G. Grossman, and K. Rogoff. North Holland.

\footnotetext{
${ }^{23}$ For the exchange rate and terms of trade the mean is 0.3 , since these are expressed in log-differences.
} 
Baxter, M., and M. Crucini (1995): "Business Cycles and the Asset Structure of Foreign Trade," International Economic Review, 36, 821-854.

Benigno, P. (2001): "Price Stability with Imperfect Financial Integration," unpublished, New York University.

Bergin, P. (2003): "Putting the 'New Open Economy Macroeconomics' to a Test," Journal of International Economics, 60(1), 3-34.

- (2004): "How well can the New Open Economy Macroeconomics Explain the Exchange Rate and the Current Account," unpublished, University of California Davis.

Boivin, J., and M. Giannoni (2006): "DSGE Models in a Data-Rich Environment," NBER Working Paper no. 12772.

Boldrin, M., L. J. Christiano, and J. D. M. Fisher (2001): "Habit Persistence, Asset Returns, and the Business Cycle," American Economic Review, 91(1), 149-166.

Bowden, R., And V. Martin (1995): "International Business Cycles and Financial Integration," The Review of Economics and Statistics, 77, 305-320.

Burstein, A., C. Kurz, and L. Tesar (2008): "Trade, Production Sharing, and the International Transmission of Business Cycles," unpublished, UCLA.

Christiano, L. J., M. Eichenbaum, and C. L. Evans (2005): "Nominal Rigidities and the Dynamic Effects of a Shock to Monetary Policy," Journal of Political Economy, 113, 1.

Cushman, D. O., and T. Zha (1997): "Identifyiung monetary policy in a small open economy under flexible exchange rates," Journal of Monetary Economics, 39, 433-448.

De Walque, G., F. Smets, and R. Wouters (2005): "An Open Economy DSGE Model Linking the Euro Area and the US Economy," unpublished, National Bank of Belguim.

Del Negro, M. (2003): "Fear of Floating? A Structural Estimation of Monetary Policy in Mexico," unpublished, Federal Reserve Bank of Atlanta.

Devereux, M. B., And C. Engel (2002): "Exchange rate pass-through, exchange rate volatility, and exchange rate disconnect," Journal of Monetary Economics, 49, 913-940.

Eldridge, L. P., And M. K. Sherwood (2001): "A Perspective on U.S.-Canada Manufacturing Productivity Gap," Monthly Labor Review, pp. 31-48.

Elliot, G., J. Stock, and T. Rotehnberg (1996): "Efficient Tests for An Autoregressive Unit Root," Econometrica, (64), 813-836.

Erceg, C. J., D. W. Henderson, and A. T. Levin (2000): "Optimal Monetary Policy with Staggered Wage and Price Contracts," Journal of Monetary Economics, 46(281-313).

Fernandez-Villaverde, J., J. F. Rubio-Ramirez, M. Watson, and T. Sargent (2006): “A, B, C's and (D)'s For Understanding VARS," American Economic Review, $97(3), 1021$. 
Gali, J. (1999): "Technology, Employment and the Business Cycle: Do Technology Shocks Explain the Business Cycle," American Economic Review, 249, 249-271.

Gali, J., and T. Monacelli (2005): "Monetary Policy and Exchange Rate Volatility in a Small Open Economy," Review of Economic Studies, 72.

Gali, J., and P. Rabanal (2004): "Technology Shocks and Aggregate Fluctuations: How Well Does the RBC Model Fit Postwar U.S. Data?," NBER Macroeconomics Annual.

Ghironi, F. (2000): "Towards and New Open Economy Macroeconometrics," Boston College Economics Department Working Paper No. 469.

Huang, K., And Z. Liu (2007): "Business Cycles with Staggered Prices and International Trade in Intermediate Goods," Journal of Monetary Economics, 54, 1271-1289.

Ireland, P. (2004): "Technology Shocks in the New Keynesian Model," The Review of Economics and Statistics, 86(4), 923-936.

Justiniano, A. (2007): "Factoring In Canadian Cycles," in Northern Star - Canada's Path to Economic Prosperity, ed. by T. Bayoumi. International Monetary Fund.

Justiniano, A., And B. Preston (2006): "Can Structural Small Open Economy Models Account for the Influence of Foreign Shocks," CAMA Working Paper Series no. 12.

Kollmann, R. (2002): "Monetary Policy Rules in the Open Economy: Effects on Welfare and Business Cylces," Journal of Monetary Economics, 49, 989-1015.

Kose, M. A., C. Otrok, and C. H. Whiteman (2008): "Understanding the Evolution of World Business Cycles," Journal of International Economics, 75(1), 110-130.

Lubik, T. A., And F. Schorfheide (2005a): "A Bayesian Look at New Open Economy Macroeconomics," in NBER Macroeconomics Annual, ed. by M. Gertler. NBER.

_ (2005b): "Do Central Banks Respond to Exchange Rate Movements? A Structural Investigation," Journal of Monetary Economics, 54(4), 1069-1087.

Lubik, T. A., And W. L. Teo (2005): "Do World Shocks Drive Domestic Business Cycles? Some Evidenec from Structural Estimation," unpublished, Johns Hopkins University.

Lumsdaine, R., and E. Prasad (2003): "Identifying the Common Component if International Fluctuations: A New Approach," The Economic Journal, 113, 101-127.

McCallum, B. T., and E. Nelson (2000): "Monetary Policy for an Open Economy: An Alternative Framework with Optimizing Agents and Sticky Prices," Oxford Review of Economic Policy, (16), 74-91.

Monacelli, T. (2005): "Monetary Policy in a Low Pass-through Environment," Journal of Money, Credit and Banking, 37, 1047-1066.

NG, S., And P. Perron (2001): "Lag Selection and the Construction of Unit Root Tests with Good Size and Power," Econometrica, 69(6), 1519-1554. 
Rabanal, P., and V. Tuesta (2005): "Euro-Dollar Real Exchange Rate Dynamics in an Estimated Two-country Model: What is Important and What is Not," unpublished, International Monetary Fund and Banco Central de Reserva del Peru.

Rios-Rull, J.-V., C. Fuentes-Albero, R. Santaeulalia-Llopisand, M. Kryshko, And F. Schorfheide (2007): "Methods versus Substance: Measuring the Effects of Technology Shocks," .

Schmitt-Grohe, S. (1998): "The International Transmission of Economic Fluctuations: Effects of US Business Cycles on the Canadian Economy," Journal of International Economics, $44,257-287$.

Schmitt-Grohe, S., And M. Uribe (2003): "Closing Small Open Economy Models," Journal of International Economics, 61, 163-195.

Schorfheide, F. (2000): "Loss Function-Based Evaluation of DSGE Models," Journal of Applied Econometrics, 15, 645-670.

Smets, F., And R. Wouters (2007): "Shocks and Frictions in US Business Cycles: a Bayesian DSGE Approach," American Economic Association, 97(3), 586-606.

Stockman, A. C., and L. L. Tesar (1995): "Tastes and Technology in a Two-country Model of the Business Cycle: Explaining International Comovements," American Economic Review, 85(1), 168-185.

Woodford, M. (2003): Interest and Prices: Foundations of a Theory of Monetary Policy. Princeton University Press.

Zна, T. (1999): "Block Recursion and Structural Vector Autoregression," Journal of Econometrics, 90, 291-316. 
Figure 1: Data and model implied cross-correlations Canada-U.S. Data (dark), DSGE median (grey) and [ 5,95$]$ posterior bands (dashed)
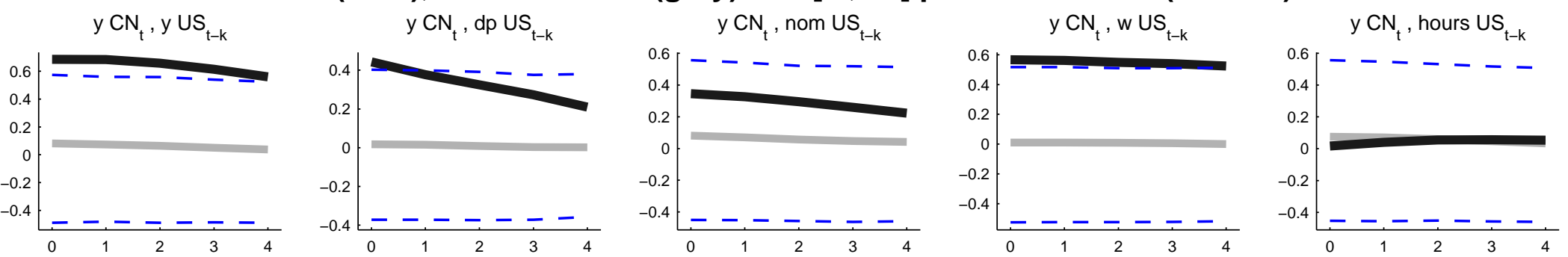

$\operatorname{dp} \mathrm{CN}_{\mathrm{t}}, \mathrm{y} \mathrm{US}_{\mathrm{t}-\mathrm{k}}$

$d p \mathrm{CN}_{t}, \mathrm{dp} U \mathrm{~S}_{\mathrm{t}-\mathrm{k}}$
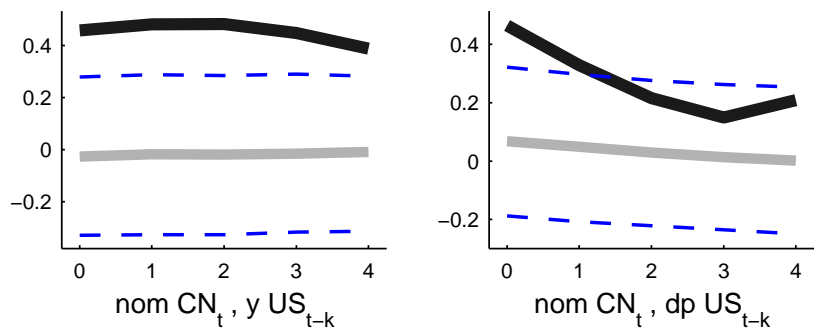

dp $\mathrm{CN}_{\mathrm{t}}$, nom US $\mathrm{t}_{\mathrm{t}-\mathrm{k}}$

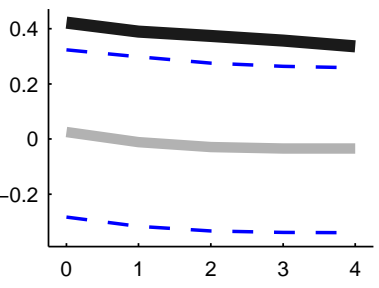

dp $\mathrm{CN}_{\mathrm{t}}$, w US

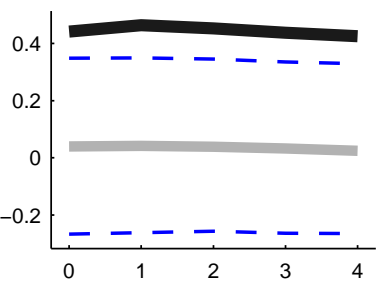

dp $\mathrm{CN}_{\mathrm{t}}$, hours US
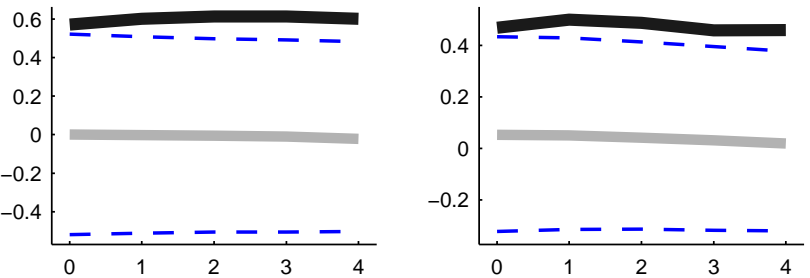

nom $\mathrm{CN}_{t}$, nom US $\mathrm{t}_{\mathrm{t}-\mathrm{k}}$

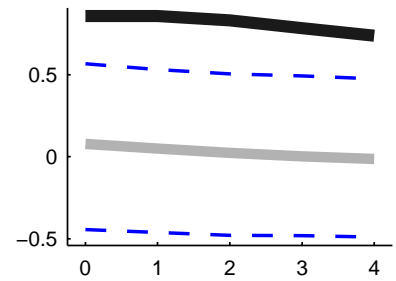

nom $\mathrm{CN}_{t}$, w US ${ }_{t-k}$
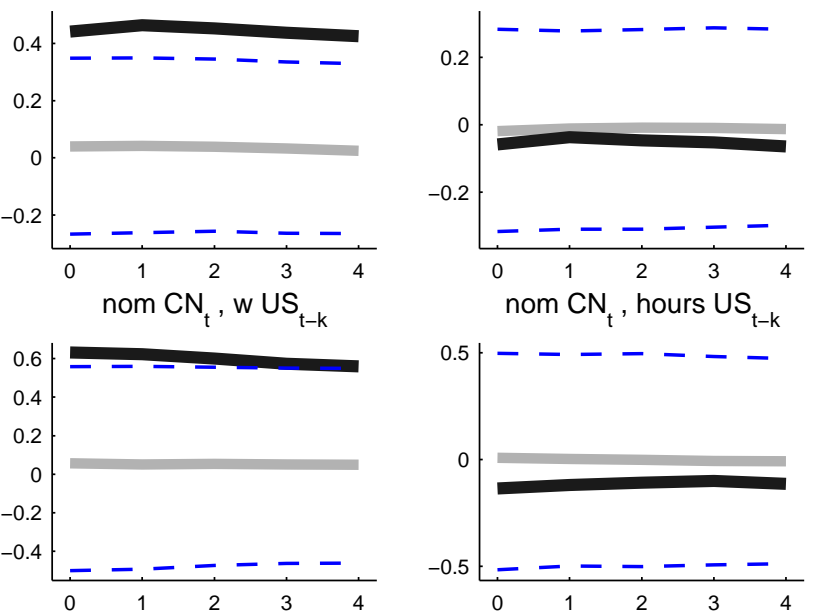

nom $\mathrm{CN}_{\mathrm{t}}$, hours $\mathrm{US}_{\mathrm{t}-\mathrm{k}}$

$w \mathrm{CN}_{\mathrm{t}}, \mathrm{y} \mathrm{US}_{\mathrm{t}-\mathrm{k}}$

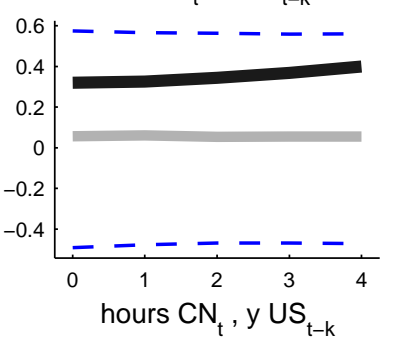

w $\mathrm{CN}_{\mathrm{t}}, \mathrm{dp} \mathrm{US}_{\mathrm{t}-\mathrm{k}}$
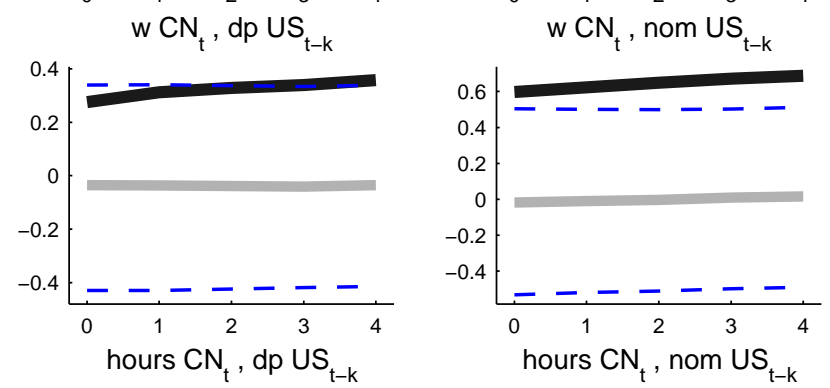

$w \mathrm{CN}_{t}, w \cup \mathrm{S}_{\mathrm{t}-\mathrm{k}}$

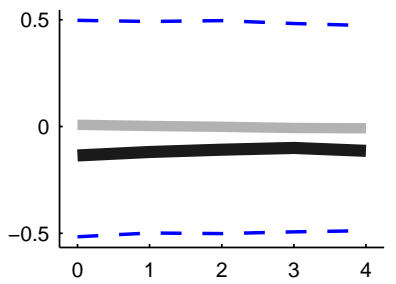

w $\mathrm{CN}_{\mathrm{t}}$, hours $\mathrm{US}_{\mathrm{t}-\mathrm{k}}$
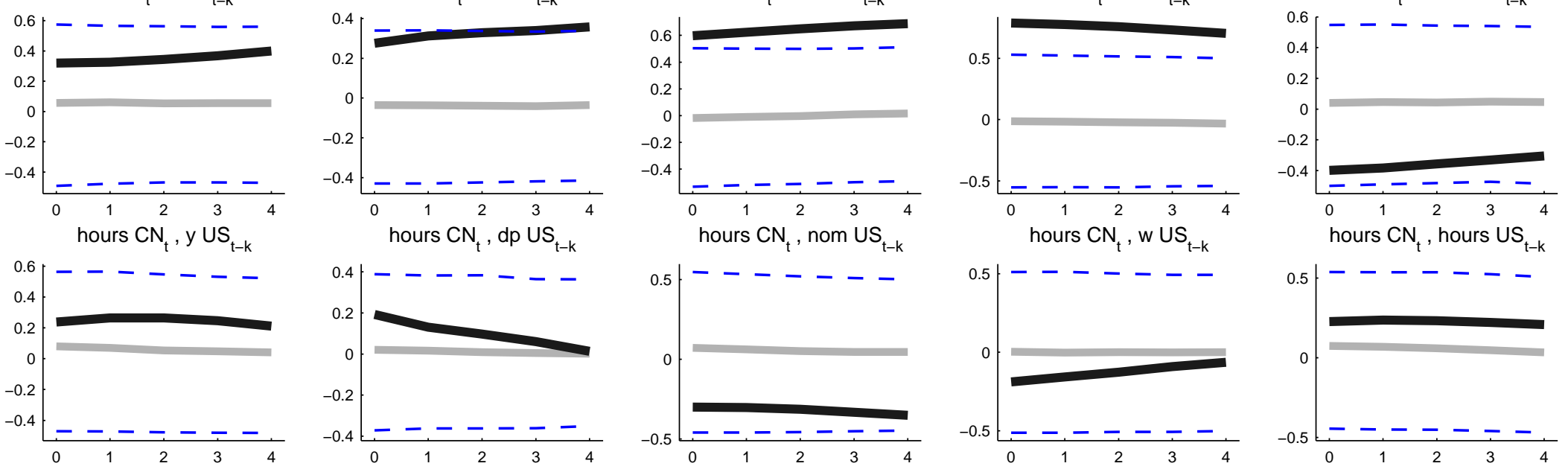

Legend: $y$ (output), dp (inflation), nom (nominal interest rate), w (real wage) and hours. X-axis: K lags of U.S. variables, 0 through 4. 


\title{
Table 1: Posterior Variance Shares ${ }^{1}$ of Canadian Series Attributed to All U.S. Shocks in a SUR model
}

\author{
Median variance shares and [5,95] posterior bands for all U.S. shocks ${ }^{2}$
}

\begin{tabular}{|c|c|c|c|c|}
\hline Soriec & \multicolumn{2}{|c|}{1 quarter horizon } & \multicolumn{2}{|c|}{4 quarter horizon } \\
\hline Output & 0.22 & {$[0.07,0.41]$} & 0.44 & {$[0.19,0.68]$} \\
\hline Inflation & 0.20 & {$[0.06,0.39$ ] } & 0.37 & {$[0.14,0.63]$} \\
\hline Interest Rate & 0.14 & {$[0.03,0.31]$} & 0.37 & {$[0.14,0.63]$} \\
\hline Real Wages & 0.13 & {$[0.03,0.28]$} & 0.34 & {$[0.12,0.59$ ] } \\
\hline Hours & 0.07 & {$[0.02,0.16]$} & 0.25 & {$[0.08,0.48]$} \\
\hline Real Exchange Rate & 0.07 & {$[0.01,0.17$ ] } & 0.17 & {$[0.06,0.35]$} \\
\hline Terms of Trade & 0.12 & {$[0.03,0.26$ ] } & 0.22 & {$[0.08,0.40]$} \\
\hline Series & \multicolumn{2}{|c|}{8 quarter horizon } & \multicolumn{2}{|c|}{ Stationary Variance $^{3}$} \\
\hline Output & 0.52 & {$[0.25,0.76]$} & 0.76 & {$[0.44,0.98]$} \\
\hline Inflation & 0.42 & {$[0.20,0.69]$} & 0.65 & {$[0.33,0.95]$} \\
\hline Interest Rate & 0.47 & {$[0.21,0.73]$} & 0.71 & {$[0.40,0.97]$} \\
\hline Real Wages & 0.49 & {$[0.22,0.74]$} & 0.79 & {$[0.49,0.98$ ] } \\
\hline Hours & 0.42 & {$[0.16,0.69]$} & 0.75 & {$[0.43,0.98]$} \\
\hline Real Exchange Rate & 0.26 & {$[0.10,0.49]$} & 0.62 & {$[0.29,0.95]$} \\
\hline Terms of Trade & 0.29 & {$[0.13,0.49$ ] } & 0.57 & {$[0.27,0.92]$} \\
\hline
\end{tabular}

Notes:

1 Variance shares cover [0,1] interval. Hence 0.01 corresponds to 1 percent.

2 Median of the sum of all five U.S. shocks computed for each draw of the SUR parameters obtained with a Gibbs simulator. Details of the SUR are given in Appendix B. Mean shares are very similar and if anything slighlty higher in some cases.

3 Stationary refers to the long-horizon variance. 
Table 2: Prior densities and posterior estimates for baseline model (domestic block)

\begin{tabular}{|c|c|c|c|c|c|c|c|c|}
\hline \multirow[b]{2}{*}{ Coefficient } & \multirow[b]{2}{*}{ Description } & \multicolumn{3}{|c|}{ Prior } & \multicolumn{4}{|c|}{ Posterior $^{2}$} \\
\hline & & Prior Density ${ }^{1}$ & Mean & Std & Median & Std & [ 5 & $95]$ \\
\hline$\varphi$ & Inverse Frisch & $\mathrm{N}$ & 1.00 & 0.30 & 1.27 & 0.27 & {$[0.84$} & , 1.72$]$ \\
\hline$\sigma$ & Intertemporal ES & $\mathrm{N}$ & 1.00 & 0.40 & 1.43 & 0.30 & [ 0.98 & , 1.95 ] \\
\hline$\alpha_{H}$ & Calvo domestic prices & B & 0.60 & 0.10 & 0.86 & 0.04 & {$[0.78$} & , 0.92$]$ \\
\hline$\alpha_{F}$ & Calvo import prices & $\mathrm{B}$ & 0.50 & 0.20 & 0.42 & 0.06 & {$[0.33$} & $, 0.52]$ \\
\hline$\alpha_{W}$ & Calvo wages & B & 0.60 & 0.10 & 0.88 & 0.04 & {$[0.79$} & , 0.93$]$ \\
\hline$\gamma_{H}$ & Indexation domestic prices & B & 0.50 & 0.20 & 0.42 & 0.12 & {$[0.25$} & $, 0.63]$ \\
\hline$\gamma_{W}$ & Indexation wages & B & 0.50 & 0.20 & 0.22 & 0.11 & {$[0.07$} & $, 0.44]$ \\
\hline$h$ & Habit & B & 0.50 & 0.10 & 0.64 & 0.06 & {$[0.53$} & $, 0.73]$ \\
\hline$\tau$ & Openess & $\mathrm{B}$ & 0.29 & 0.02 & 0.24 & 0.02 & {$[0.21$} & $, 0.27]$ \\
\hline$\eta$ & Elasticity H-F goods & $\mathrm{N}$ & 0.90 & 0.10 & 0.86 & 0.09 & {$[0.70$} & , 1.01$]$ \\
\hline$\theta_{\pi}$ & Taylor rule, inflation & $\mathrm{N}$ & 1.80 & 0.30 & 2.00 & 0.26 & {$[1.57$} & $2.42]$ \\
\hline$\theta_{y}$ & Taylor rule, output & G & 0.25 & 0.13 & 0.21 & 0.08 & {$[0.09$} & $0.34]$ \\
\hline$\theta_{d y}$ & Taylor rule, output growth & $\mathrm{N}$ & 0.30 & 0.20 & 0.70 & 0.18 & {$[0.42$} & , 1.00$]$ \\
\hline$\theta_{d e}$ & Taylor rule, nominal exchange rate & G & 0.30 & 0.20 & 0.31 & 0.10 & {$[0.17$} & , 0.50$]$ \\
\hline$\theta_{i}$ & Taylor rule, smoothing & $\mathrm{B}$ & 0.60 & 0.20 & 0.88 & 0.02 & {$[0.84$} & , 0.91$]$ \\
\hline$\rho_{a}$ & Technology & $\mathrm{B}$ & 0.60 & 0.20 & 0.94 & 0.02 & [ 0.91 & , 0.96$]$ \\
\hline$\rho_{g}$ & Preferences & $\mathrm{B}$ & 0.60 & 0.20 & 0.92 & 0.02 & {$[0.88$} & , 0.95$]$ \\
\hline$\rho_{L}$ & labor disutility & $\mathrm{B}$ & 0.60 & 0.20 & 0.51 & 0.12 & {$[0.30$} & $, 0.70]$ \\
\hline$\rho_{c p, F}$ & Cost-push imports & B & 0.60 & 0.20 & 0.92 & 0.03 & {$[0.87$} & $, 0.96]$ \\
\hline$\rho_{r p}$ & Risk premium & B & 0.60 & 0.20 & 0.98 & 0.01 & {$[0.96$} & , 0.99$]$ \\
\hline$\sigma_{a}$ & sd technology & I & 0.50 & 1.00 & 0.52 & 0.04 & [ 0.46 & , 0.59$]$ \\
\hline$\sigma_{i}$ & sd monetary policy & I & 0.15 & 1.00 & 0.21 & 0.02 & [ 0.18 & , 0.25$]$ \\
\hline$\sigma_{g}$ & sd preferences & I & 1.00 & 1.00 & 4.32 & 0.96 & [ 3.05 & , 6.10$]$ \\
\hline$\sigma_{c p, H}$ & sd cost-push domestic & I & 0.15 & 1.00 & 0.70 & 0.07 & [ 0.61 & $, 0.83]$ \\
\hline$\sigma_{L}$ & sd labor disutility & I & 2.00 & 1.00 & 3.51 & 1.79 & [ 1.68 & , 7.37 ] \\
\hline$\sigma_{c p, F}$ & sd cost-push imports & I & 1.00 & 1.00 & 2.12 & 0.60 & {$[1.37$} & , 3.32$]$ \\
\hline$\sigma_{r p}$ & sd risk premium & I & 1.00 & 1.00 & 0.31 & 0.03 & [ 0.26 & $, 0.38]$ \\
\hline
\end{tabular}

(continued in the next page with the foreign block) 
Table 2: Prior densities and posterior estimates for baseline model (foreign block)

\begin{tabular}{|c|c|c|c|c|c|c|c|c|}
\hline \multirow[b]{2}{*}{ Coefficient } & \multirow[b]{2}{*}{ Description } & \multicolumn{3}{|c|}{ Prior } & \multicolumn{4}{|c|}{ Posterior ${ }^{2}$} \\
\hline & & Prior Density ${ }^{1}$ & Mean & Std & Median & Std & [ 5 & , 95$]$ \\
\hline$\varphi^{*}$ & Inverse Frisch & $\mathrm{N}$ & 1.00 & 0.30 & 1.19 & 0.27 & {$[0.77$} & $, 1.65]$ \\
\hline$\sigma^{*}$ & Intertemporal ES & $\mathrm{N}$ & 1.00 & 0.40 & 0.99 & 0.27 & {$[0.62$} & $, 1.48]$ \\
\hline$\alpha_{H^{*}}$ & Calvo prices & $\mathrm{B}$ & 0.60 & 0.10 & 0.91 & 0.02 & [ 0.86 & $, 0.94]$ \\
\hline$\alpha_{W^{*}}$ & Calvo wages & B & 0.60 & 0.10 & 0.87 & 0.03 & {$[0.81$} & , 0.91$]$ \\
\hline$\gamma_{H^{*}}$ & Indexation prices & B & 0.50 & 0.20 & 0.58 & 0.12 & {$[0.40$} & $, 0.79]$ \\
\hline$\gamma_{W^{*}}$ & Indexation wages & B & 0.50 & 0.20 & 0.29 & 0.16 & {$[0.09$} & $, 0.60]$ \\
\hline$h^{*}$ & Habit & $\mathrm{B}$ & 0.50 & 0.10 & 0.56 & 0.07 & {$[0.45$} & $, 0.68]$ \\
\hline$\lambda *$ & Elasticity foreign demand & $\mathrm{N}$ & 1.50 & 0.50 & 0.54 & 0.11 & {$[0.38$} & $, 0.74]$ \\
\hline$\theta_{\pi^{*}}$ & Taylor rule, inflation & $\mathrm{N}$ & 1.80 & 0.30 & 1.76 & 0.26 & [ 1.35 & $2.19]$ \\
\hline$\theta_{y^{*}}$ & Taylor rule, output & G & 0.25 & 0.13 & 0.19 & 0.06 & {$[0.09$} & $, 0.28]$ \\
\hline$\theta_{d y^{*}}$ & Taylor rule, output growth & $\mathrm{N}$ & 0.30 & 0.20 & 0.77 & 0.15 & {$[0.54$} & $, 1.02]$ \\
\hline$\theta_{i^{*}}$ & Taylor rule, smoothing & $\mathrm{B}$ & 0.60 & 0.20 & 0.85 & 0.02 & {$[0.81$} & $, 0.88]$ \\
\hline$\rho_{a^{*}}$ & Technology & $\mathrm{B}$ & 0.80 & 0.15 & 0.93 & 0.02 & {$[0.90$} & , 0.97$]$ \\
\hline$\rho_{g^{*}}$ & Preferences & B & 0.80 & 0.15 & 0.90 & 0.03 & {$[0.85$} & $, 0.94]$ \\
\hline$\rho_{L^{*}}$ & labor disutility & $\mathrm{B}$ & 0.80 & 0.15 & 0.37 & 0.08 & {$[0.23$} & $, 0.51]$ \\
\hline$\sigma_{a^{*}}$ & sd technology & I & 1.00 & 2.00 & 0.47 & 0.04 & {$[0.42$} & , 0.53$]$ \\
\hline$\sigma_{i^{*}}$ & sd monetary policy & I & 0.25 & 2.00 & 0.13 & 0.01 & {$[0.11$} & $, 0.15]$ \\
\hline$\sigma_{g^{*}}$ & sd preferences & I & 2.00 & 2.00 & 2.55 & 0.44 & [ 1.92 & , 3.35 ] \\
\hline$\sigma_{g^{*}}$ & sd cost-push & I & 0.25 & 2.00 & 0.22 & 0.02 & [ 0.19 & $, 0.26]$ \\
\hline$\sigma L^{*}$ & sd labor disutility & I & 4.00 & 2.00 & 3.41 & 0.89 & [ 2.33 & $, 5.22]$ \\
\hline
\end{tabular}

Relative to the text, the standard deviations of the innovations are scaled by 100 for the estimation, which is reflected in the prior and posterior estimates.

1 N stands for Normal, B Beta, G Gamma and I Inverted-Gamma1 distribution

${ }^{2}$ Median and posterior percentiles from 4 chains of 100,000 draws generated using a Random walk Metropolis algorithm, where we discard the initial 50,000 and retain one in every 5 subsequent draws. For convergence we monitor trace plots as well as the potential scale reduction factors both for the variances and $90 \%$ posterior probability bands. 


\title{
Table 3: Prior Variance Shares ${ }^{1}$ of Canadian Series Attributed to All U.S. Shocks in Baseline DSGE
}

\author{
Mean variance shares and [5,95] prior bands for all U.S. shocks ${ }^{2}$
}

\begin{tabular}{|c|c|c|c|c|}
\hline Soritec & \multicolumn{2}{|c|}{1 quarter horizon } & \multicolumn{2}{|c|}{4 quarter horizon } \\
\hline Output & 0.37 & {$[0.01,0.96]$} & 0.38 & {$[0.01,0.97]$} \\
\hline Inflation & 0.47 & {$[0.01,0.98]$} & 0.55 & {$[0.02,0.99]$} \\
\hline Interest Rate & 0.43 & {$[0.02,0.97]$} & 0.55 & {$[0.03,0.99]$} \\
\hline Real Wages & 0.19 & {$[0.00,0.80]$} & 0.24 & {$[0.00,0.83]$} \\
\hline Hours & 0.31 & {$[0.01,0.93]$} & 0.36 & {$[0.01,0.96]$} \\
\hline Real Exchange Rate & 0.41 & {$[0.02,0.96]$} & 0.51 & {$[0.04,0.96]$} \\
\hline Terms of Trade & 0.47 & {$[0.02,0.97]$} & 0.56 & {$[0.03,0.97]$} \\
\hline Series & \multicolumn{2}{|c|}{8 quarter horizon } & \multicolumn{2}{|c|}{ Stationary Variance ${ }^{3}$} \\
\hline Output & 0.37 & {$[0.00,0.97]$} & 0.39 & {$[0.00,0.98]$} \\
\hline Inflation & 0.57 & {$[0.02,0.99]$} & 0.59 & {$[0.02,1.00]$} \\
\hline Interest Rate & 0.58 & {$[0.03,0.99$ ] } & 0.60 & {$[0.02,1.00]$} \\
\hline Real Wages & 0.30 & {$[0.00,0.91]$} & 0.37 & {$[0.00,0.97]$} \\
\hline Hours & 0.36 & {$[0.00,0.96$ ] } & 0.38 & {$[0.00,0.98]$} \\
\hline Real Exchange Rate & 0.52 & {$[0.05,0.97]$} & 0.54 & {$[0.05,0.97]$} \\
\hline Terms of Trade & 0.56 & {$[0.03,0.97$ ] } & 0.58 & {$[0.03,0.97$ ] } \\
\hline
\end{tabular}

Notes:

1 Variance shares cover $[0,1]$ interval. Hence 0.37 corresponds to 37 percent.

2 Mean of the sum of the shares for all five U.S. shocks computed for each 100,000 parameters drawn randomly from the priors in table 1 . We report means since domestic and foreign shares add up to one for each draw, but medians are very similar and slighlty higher in some cases.

3 Stationary refers to the long-horizon variance. 


\section{Table 4: $\underline{\text { Posterior Variance Shares }}{ }^{1}$ of Canadian Series Attributed to All U.S. Shocks in Baseline DSGE}

Median variance shares and $[5,95]$ posterior bands for all U.S. shocks ${ }^{2}$

Series

Output

Inflation

Interest Rate

Hours

Real Wages

Real Exchange Rate

Terms of Trade

Series

Output

Inflation

Interest Rate

Hours

Real Wages

Real Exchange Rate

Terms of Trade
1 quarter horizon

\begin{tabular}{ll}
\hline \hline 0.01 & {$[0.01,0.02]$} \\
0.01 & {$[0.01,0.02]$} \\
0.03 & {$[0.02,0.04]$} \\
0.00 & {$[0.00,0.01]$} \\
0.01 & {$[0.01,0.01]$} \\
0.03 & {$[0.02,0.03]$} \\
0.04 & {$[0.02,0.06]$}
\end{tabular}

8 quarter horizon

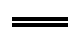

$$
0.01 \quad[0.01,0.02]
$$

$0.01 \quad[0.01,0.02]$

$0.01[0.01,0.02]$

$0.00[0.00,0.01]$

$0.01 \quad[0.01,0.02]$

$0.03[0.02,0.04]$

$0.05[0.03,0.07]$
4 quarter horizon

\begin{tabular}{ll}
\hline \hline & \\
0.01 & {$[0.01,0.02]$} \\
0.01 & {$[0.01,0.02]$} \\
0.02 & {$[0.01,0.03]$} \\
0.00 & {$[0.00,0.01]$} \\
0.01 & {$[0.01,0.01]$} \\
0.03 & {$[0.02,0.04]$} \\
0.04 & {$[0.03,0.06]$}
\end{tabular}

Stationary Variance ${ }^{3}$

\begin{tabular}{|c|c|}
\hline 0.01 & {$[0.01,0.02]$} \\
\hline 0.01 & {$[0.01,0.02]$} \\
\hline 0.01 & {$[0.01,0.02]$} \\
\hline 0.01 & {$[0.00,0.02]$} \\
\hline 0.01 & {$[0.00,0.02]$} \\
\hline 0.03 & {$[0.02,0.04]$} \\
\hline 0.05 & {$[0.03,0.07]$} \\
\hline
\end{tabular}

Notes:

1 Variance shares cover [0,1] interval. Hence 0.01 corresponds to 1 percent.

2 Median of the sum of the shares for all five U.S. shocks computed with the posterior simulators of model parameters. We report means since domestic and foreign shares add up to one for each draw, but clearly given the tight posterior bands the medians are almost identical.

3 Stationary refers to the long-horizon variance. 


\section{Table 5: Variance Shares ${ }^{1}$ of Canadian Series Attributed to All U.S. Shocks in Alternative Specifications}

\begin{tabular}{lccccc} 
Specification & Baseline ${ }^{2}$ & $\begin{array}{c}\text { Uniform } \\
\text { prior on } \\
\text { volatilities }\end{array}$ & $\begin{array}{c}\text { Output and } \\
\text { wages in } \\
\text { first } \\
\text { differences }\end{array}$ & $\begin{array}{c}\text { RER and } \\
\text { TOT in } \\
\text { levels }\end{array}$ & $\begin{array}{c}\text { Response } \\
\text { to foreign } \\
\text { interest } \\
\text { rate in } \\
\text { policy } \\
\text { rule }^{4}\end{array}$ \\
\hline \hline \multicolumn{1}{c}{ Series \Horizon } & Horizon 1 & Horizon 1 & Horizon 12 & Horizon 12 & Stationary $^{5}$ \\
\hline Output & 0.01 & 0.02 & 0.01 & 0.01 & 0.01 \\
Inflation & 0.01 & 0.01 & 0.01 & 0.02 & 0.02 \\
Interest Rate & 0.03 & 0.03 & 0.01 & 0.01 & 0.01 \\
Real Wages & 0.00 & 0.01 & 0.01 & 0.01 & 0.03 \\
Hours & 0.01 & 0.01 & 0.01 & 0.01 & 0.01 \\
Real Exchange Rate & 0.03 & 0.03 & 0.03 & 0.05 & 0.03 \\
Terms of Trade & 0.04 & 0.05 & 0.04 & 0.14 & 0.06 \\
\hline
\end{tabular}

Notes:

1 Variance shares cover [0,1] interval. Hence 0.01 corresponds to 1 percent. These are computed at the mode of each specification. We select the horizon with the highest share for output. All shocks are independent from one another.

2 Reproduced from table 4

3 Prior for all domestic and foreign standard deviations is Uniform [1e-4,10].

4 Policy rule in Canada includes a direct response to lagged U.S. interest rates. The results are identical if we include instead a contemporaneous response to U.S. interest rate realizations.

5 Stationary refers to the long-horizon variance. 
Table 6: Variance Shares ${ }^{1}$ of Canadian Series Attributed to All U.S. Shocks in Specifications with Common Shocks

Panel A. One Common Shock Only ${ }^{2}$

\begin{tabular}{lcccc}
\hline Technology & Labor & Cost-Push & $\begin{array}{c}\text { Monetary } \\
\text { Policy }\end{array}$ & Preference \\
& Disutility & & Polich
\end{tabular}

\begin{tabular}{lccccc}
\hline Series $\backslash$ Horizon & 1 Period & Stationary & 1 Period & 1 Period & 1 Period \\
\hline \hline & & & & & \\
Output & 0.02 & 0.02 & 0.02 & 0.10 & 0.11 \\
Inflation & 0.01 & 0.06 & 0.11 & 0.00 & 0.02 \\
Interest Rate & 0.03 & 0.04 & 0.05 & 0.23 & 0.04 \\
Real Wages & 0.00 & 0.13 & 0.04 & 0.00 & 0.01 \\
Hours & 0.21 & 0.01 & 0.01 & 0.06 & 0.08 \\
Real Exchange Rate & 0.02 & 0.04 & 0.02 & 0.01 & 0.04 \\
Terms of Trade & 0.04 & 0.08 & 0.03 & 0.01 & 0.06 \\
\hline
\end{tabular}

Panel B. All Common Shocks Simultaneously ${ }^{3}$

\begin{tabular}{lcccc} 
Series $\backslash$ Horizon $^{5}$ & 1 Period & 4 Periods & 8 Periods & Stationary \\
\hline \hline & & & & \\
Output & 0.23 & 0.20 & 0.18 & 0.16 \\
Inflation & 0.11 & 0.13 & 0.13 & 0.13 \\
Interest Rate & 0.26 & 0.22 & 0.18 & 0.12 \\
Real Wages & 0.13 & 0.16 & 0.17 & 0.16 \\
Hours & 0.30 & 0.26 & 0.24 & 0.23 \\
Real Exchange Rate & 0.00 & 0.00 & 0.00 & 0.00 \\
Terms of Trade & 0.00 & 0.01 & 0.01 & 0.01 \\
\hline
\end{tabular}

Notes:

1 Variance shares cover [0,1] interval. Hence 0.01 corresponds to 1 percent. Disturbances in Canada are given by the sum of two orthogonal components: a country-specific shocks and a disturbance in common with the corresponding U.S. shock. These shares now include the variability attributed to the common component(s) of the corresponding Canadian composite disturbance.

2 Each specification has a common component in that disturbance only. These are computed at the mode. We report the horizon with the highest share for output.

3 All 5 shocks from Panel A now have a common component with the corresponding U.S. disturbances. These variance shares are computed at the mode. We report the same horizons as in tables 1,3 and 4. 